\title{
Interactions Between the Toxin Kid of the Bacterial parD System and the Antitoxins Kis and MazE
}

\author{
Monique B. Kamphuis, ${ }^{1}$ Maria Chiara Monti, ${ }^{2}$ Robert H. H. van den Heuvel, ${ }^{2}$ Sandra Santos-Sierra, ${ }^{3}$ \\ Gert E. Folkers, ${ }^{1}$ Marc Lemonnier, ${ }^{3}$ Ramón Díaz-Orejas, ${ }^{3}$ Albert J. R. Heck, ${ }^{2}$ and Rolf Boelens ${ }^{1 *}$ \\ ${ }^{1}$ Bijvoet Center for Biomolecular Research, Department of NMR Spectroscopy, Utrecht University, 3584 CH Utrecht, \\ The Netherlands \\ ${ }^{2}$ Department of Biomolecular Mass Spectrometry, Bijvoet Center for Biomolecular Research and Utrecht Institute \\ for Pharmaceutical Sciences, Utrecht University, 3584 CA Utrecht, The Netherlands \\ ${ }^{3}$ Departamento de Microbiología Molecular, Centro de Investigaciones Biológicas, E-28040 Madrid, Spain
}

ABSTRACT The proteins Kid and Kis are the toxin and antitoxin, respectively, encoded by the parD operon of Escherichia coli plasmid R1. Kis prevents the inhibition of $E$. coli cell growth caused by the RNA cleavage activity of Kid. Overproduction of MazE, the chromosome-encoded homologue of Kis, has been demonstrated to neutralize Kid toxicity to a certain extent in the absence of native Kis. Here, we show that a high structural similarity exists between these antitoxins, using NMR spectroscopy. We report about the interactions between Kid and Kis that are responsible for neutralization of Kid toxicity and enhance autoregulation of parD transcription. Native macromolecular mass spectrometry data demonstrate that Kid and Kis form multiple complexes. At Kis:Kid ratios equal to or exceeding $1: 1$, as found in vivo in a plasmid-containing cell, various complexes are present, ranging from $\mathbf{K i d}_{2}-$ $\mathrm{Kis}_{2}$ tetramer up to $\mathrm{Kis}_{2}-\mathrm{Kid}_{2}-\mathrm{Kis}_{2}-\mathrm{Kid}_{2}-\mathrm{Kis}_{2}$ decamer. When Kid is in excess of Kis, corresponding to an in vivo situation immediately after loss of the plasmid, the $\mathrm{Kid}_{2}-\mathrm{Kis}_{2}-\mathrm{Kid}_{2}$ heterohexamer is the most abundant species. NMR chemical shift and intensity perturbations in the ${ }^{1} \mathrm{H}^{15} \mathrm{~N}$ HSQC spectra of Kid and Kis, observed when titrating the partner protein, show that the interaction sites of Kid and Kis resemble those within the previously reported $\mathrm{MazF}_{2}-\mathrm{MazE}_{2}-\mathrm{MazF}_{2}$ complex. Furthermore, we demonstrate that $\mathrm{Kid}_{2}-\mathrm{MazE}_{2}$ tetramers can be formed via weak interactions involving a limited part of the Kis-binding residues of Kid. The functional roles of the identified Kid-Kis and Kid-MazE interaction sites and complexes in toxin neutralization and repression of transcription are discussed. Proteins 2007;67:219-231. @ 2007 Wiley-Liss, Inc.

Key words: native macromolecular mass spectrometry; NMR spectroscopy; oligomerization; plasmid maintenance, proteinprotein interactions

\section{INTRODUCTION}

Eubacteria and archaea possess toxin-antitoxin (TA) systems that are involved in cell growth arrest and possi- ble cell death. ${ }^{1-3}$ Generally, TA loci encode a stable toxin and an unstable antitoxin, which form a nontoxic protein complex that represses the transcription of its operon. The antitoxins are easily degraded by cellular proteases, and if they are not replaced by newly synthesized proteins because of a general shutdown of the protein production or loss of the TA-locus containing plasmid, the toxin will exert its function. Originally discovered in plasmids, these systems were shown to increase plasmid maintenance via postsegregational killing of plasmid-free progeny. $^{2,4}$ Chromosomal TA systems, however, were recently indicated to be involved in the response to nutritional and/or environmental stress, leading to a reversible bacteriostatic state. ${ }^{2,5}$ In the long range, this can lead to cell death for particular toxins and growing conditions. ${ }^{6}$ Interest in bacterial toxins is given by a number of possible applications. They can be used in the development of new antibiotics, since many prokaryotes, including pathogens like Mycobacterium tuberculosis and Vibrio cholerae, carry multiple TA loci. ${ }^{2,7,8}$ They have also been proposed as remedy for uncontrolled cell divisions in eukaryotes, as several bacterial TA systems were shown to function in yeast and induce apoptosis in human cells. ${ }^{9-11}$

Abbreviations: HSQC, heteronuclear single quantum coherence; Kid, killing determinant; Kis, killing suppressor; $\mathrm{m} / \mathrm{z}$, mass-tocharge; TA, toxin-antitoxin.

Grant sponsor: European Union; Grant number: QLK2-CT-200000634, HPRI-CT-2001-00172; Grant sponsor: Center for Biomedical Genetics; Grant sponsor: Spanish MCyT; Grant number: SAF200204649; Grant sponsor: EU Marie Curie Fellowship; Grant number: HPMT-CT-2001-00389; Grant sponsor: Netherlands Organisation for Scientific Research (NWO); Grant number: 700.54.402.

Maria Chiara Monti's current address is: Diparimento di Scienze Farmaceutiche, Universita' di Salerno, Via Ponte Don Mellilo, 84084, Fisciano, Salerno, Italy.

Marc Lemonnier's current address is: INSERM U627, Faculté de Médecine de Nice, 28 Avenue de Valombrose, Nice 06107, France.

*Correspondence to: Rolf Boelens, Bijvoet Center for Biomolecular Research, Department of NMR Spectroscopy, Utrecht University, 3584 CH Utrecht, The Netherlands. E-mail: r.boelens@chem.uu.nl

Received 27 April 2006; Revised 11 August 2006; Accepted 11 September 2006

Published online 5 January 2007 in Wiley InterScience (www. interscience.wiley.com). DOI: 10.1002/prot.21254 
A well-characterized TA system is formed by the toxin Kid (PemK) and antitoxin Kis (PemI), encoded by the parD operon of Escherichia coli plasmid R1, ${ }^{12}$ identical to pem on plasmid R100. ${ }^{13}$ The proteins are known to form tight complexes upon simultaneous expression and purification as well as after unfolding and refolding procedures. ${ }^{14}$ Kis prevents the inhibition of $E$. coli cell growth caused by $\mathrm{Kid}^{15,16}$ and autoregulates parD transcription to a limited extend, while the coordinate action of the two proteins has been shown to efficiently repress parD transcription. ${ }^{17,18}$ The amino-terminal region of Kis is specifically involved in autoregulation, while the carboxy-terminal part of the antitoxin is indispensable for Kid inhibition but also important for an optimal regulatory activity. ${ }^{19}$ Kid and its chromosomal homologues MazF (ChpAK) and $\mathrm{ChpBK}$ were shown to be endoribonucleases that inhibit protein synthesis. ${ }^{20-26}$ In in vitro studies, it has been demonstrated that these proteins are able to cleave RNA in the absence of ribosomes, ${ }^{20-25,27}$ although it was suggested originally that MazF and ChpBK cleavage activity would involve the ribosomal A-site. ${ }^{26}$ Kid cleaves preferentially between the uracyl and adenosine in the trinucleotide RNA sequence $5^{\prime}-\mathrm{UA}(\mathrm{A} / \mathrm{C})-3^{\prime}$ of singlestranded regions. ${ }^{20,22}$ Recently, we obtained a model of the Kid-RNA complex after identification of the RNA binding site of the toxin via NMR titration studies. ${ }^{28}$

For Kid, a complex of MazF and MazE (ChpAI), and MazE in complex with antibody cAbmaz1, crystal structures have been determined. ${ }^{29-31}$ The toxins share a sequence identity of $25 \%$ and their structures are highly similar. The structure of Kis, which shares $30 \%$ sequence identity with MazE, is unknown. In this article, we present the secondary structure elements of Kis and Kid in solution, using NMR spectroscopy. Native macromolecular mass spectrometry data ${ }^{32,33}$ reveal that, depending on the molar ratio of Kid and Kis, the two proteins form multiple complexes of different stoichiometries. When Kid is present in excess of Kis, the most abundant species is a $67 \mathrm{kDa} \mathrm{Kid}{ }_{2}-\mathrm{Kis}_{2}-\mathrm{Kid}_{2}$ complex. In addition, we demonstrate that the interaction sites of Kid and Kis resemble those of the hexameric MazF-MazE complex using NMR measurements. Finally, we demonstrate that only weak interactions occur between Kid and MazE, despite the biochemical similarities of the Kis and MazE antitoxins. The importance of the identified TA interaction sites and complexes for neutralization of Kid toxicity and autoregulation of parD transcription are discussed.

\section{MATERIALS AND METHODS}

\section{Sample Preparation}

Unlabeled Kid toxin and Kis antitoxin were expressed as described previously. ${ }^{14}{ }^{15} \mathrm{~N}$-labeled and ${ }^{13} \mathrm{C} /{ }^{15} \mathrm{~N}$-labeled Kid and Kis were expressed by growing prototrofic $E$. coli TG1 cells carrying the pRG-recA-NHis plasmid ${ }^{34}$ in M9 minimal medium containing ${ }^{15} \mathrm{NH}_{4} \mathrm{Cl}(98+\%$ pure, Cambridge Isotope Laboratories), ${ }^{15} \mathrm{NH}_{4} \mathrm{Cl}$ and ${ }^{13} \mathrm{C}$-glucose $(99+\%$ pure, Isotec), respectively, for $24 \mathrm{~h}$ at $37^{\circ} \mathrm{C}$. The proteins were purified as described previously. ${ }^{28}$ Unlabeled MazE was expressed and purified like unlabeled Kis.

For the mass spectrometry experiments, samples of ${ }^{15} \mathrm{~N}$-labeled Kid, ${ }^{15} \mathrm{~N}$-labeled Kis, and unlabeled MazE were dialyzed against $100 \mathrm{mM}$ ammonium acetate buffer $\mathrm{pH} 5.8$ and incubated at $21^{\circ} \mathrm{C}$ for $10 \mathrm{~min}$. The Kid:Kis molar ratio varied from $4: 1$ to $1: 2$ and the Kid:MazE molar ratio varied from $2: 1$ to $1: 4$. The Kid concentration ranged from 5-20 $\mu M$. The samples used for the NMR experiments were dialyzed against $100 \mathrm{~m} M$ KPi buffer $\mathrm{pH} 5.8$ after which $5 \% \mathrm{D}_{2} \mathrm{O}(99.9 \%$ pure, Cambridge Isotope Laboratories) was added. The experiments for the sequential backbone assignments of Kid and Kis were performed with ${ }^{13} \mathrm{C} /{ }^{15} \mathrm{~N}$-labeled samples containing $\sim 0.4 \mathrm{mM}$ protein. The approximate concentrations of the protein samples used for the NMR titration experiments were $100 \mu M{ }^{15} \mathrm{~N}$-labeled Kid, $300 \mu M$ unlabeled Kid, $200 \mu M$ ${ }^{15} \mathrm{~N}$-labeled Kis, $250 \mu M$ unlabeled Kis, and $250 \mu M$ unlabeled MazE.

\section{NMR Experiments Assignments of the Kid and Kis chemical shifts}

For the sequential backbone assignments of Kid and Kis, 2D ${ }^{1} \mathrm{H}_{-}{ }^{15} \mathrm{~N}$ HSQC and ${ }^{1} \mathrm{H}_{-}{ }^{13} \mathrm{C}$ HSQC experiments and $3 \mathrm{D}$ HNCA, HN(CO)CA, HNCACB, CBA $(\mathrm{CO}) \mathrm{NH}$, $\mathrm{HNCO}, \mathrm{HA}(\mathrm{CA}) \mathrm{NH}$, and $\mathrm{HBA}(\mathrm{CO}) \mathrm{NH}$ experiments were recorded for both ${ }^{13} \mathrm{C} /{ }^{15} \mathrm{~N}$-labeled proteins (for a review see Sattler et al., 1999). The experiments were performed on a Bruker AVANCE $600 \mathrm{MHz}$ spectrometer, at $30^{\circ} \mathrm{C}$. All spectra were processed with the NMRPIPE software package $^{35}$ and were analyzed with NMRView. ${ }^{36}$ The chemical shift values thus obtained were analyzed with the program TALOS ${ }^{37}$ to predict the secondary structure of the Kid and Kis proteins in solution. The ${ }^{1} \mathrm{HN},{ }^{1} \mathrm{H} \alpha$, ${ }^{1} \mathrm{H} \beta,{ }^{15} \mathrm{~N},{ }^{13} \mathrm{C} \alpha,{ }^{13} \mathrm{C} \beta$, and ${ }^{13} \mathrm{CO}$ chemical shift values of both proteins are added as supplementary material and deposited in the BMRB database.

\section{${ }^{1} \mathrm{H}-{ }^{15} \mathrm{~N}$ HSQC measurements to study the protein-protein interactions}

Three chemical shift perturbation experiments were performed in which series of $2 \mathrm{D}^{1} \mathrm{H}_{-}{ }^{15} \mathrm{~N}$ SE-HSQC spectra were recorded. Unlabeled Kis respectively MazE was added to ${ }^{15} \mathrm{~N}$-labeled Kid up to a final molar ratio of toxin and antitoxin of 1:4, and unlabeled Kid was added to ${ }^{15} \mathrm{~N}$ labeled Kis up to a final molar ratio of Kid:Kis of 3:1. All spectra were recorded on a Bruker AVANCE $600 \mathrm{MHz}$ spectrometer equipped with a cryo-probe with $z$-gradients, at $30^{\circ} \mathrm{C}$. For the Kid ${ }^{1} \mathrm{H}-{ }^{15} \mathrm{~N}$ HSQC spectra, 1024 points with a spectral width of $8993 \mathrm{~Hz}$ in the direct dimension and 200 points with a spectral width of $2000 \mathrm{~Hz}$ in the indirect dimension were recorded. The number of scans was increased from 32 to 624 during the Kis titration and from 8 to 480 during the MazE titration. For the Kis ${ }^{1} \mathrm{H}-{ }^{15} \mathrm{~N}$ HSQC spectra, 1024 points with a spectral width of $7310 \mathrm{~Hz}$ in the direct dimension and 200 points with a spectral width of $2000 \mathrm{~Hz}$ in the indirect dimension were recorded. The number of scans was increased from 32 to 


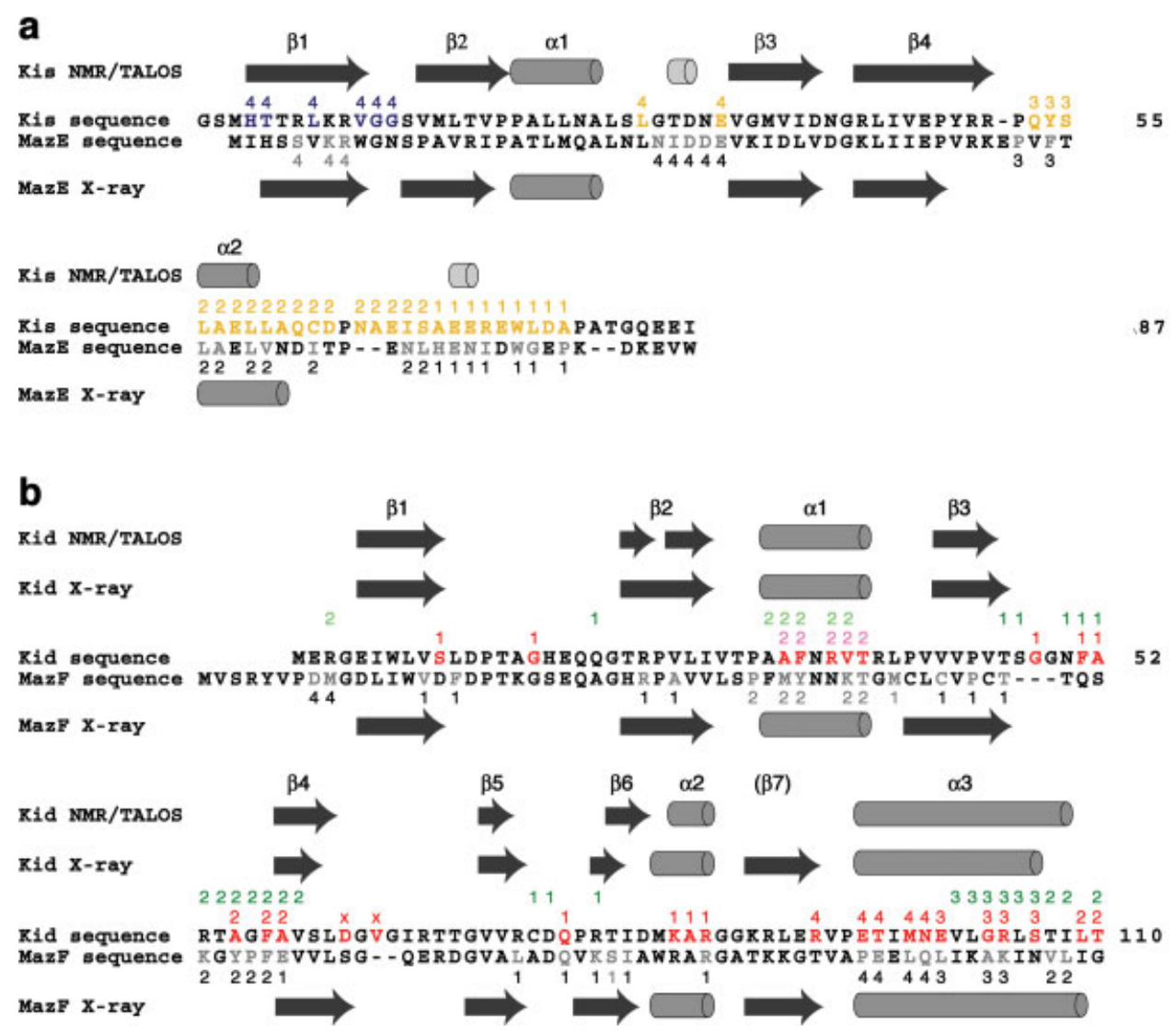

Fig. 1. Sequence alignments and secondary structure elements of (a) the antitoxins Kis and MazE and (b) the toxins Kid and MazF. $\alpha$-helices are depicted as light grey cylinders, $\beta$-strands as dark grey arrows, and helical turns as very light grey cylinders. The method used to determine the secondary structure, NMR/ TALOS as described in the main text or X-ray spectroscopy, is mentioned. Kid and Kis were studied as free proteins (PDB of the Kid crystal structure: $1 \mathrm{M} 1 \mathrm{~F}$ ), while the structural elements of MazF and MazE were derived from their heterohexamer complex (PDB: 1UB4). To allow a comparison of our data with that of Burley and coworkers, ${ }^{30}$ the amino-terminal GS residues preceding the starting methionine of MazE have been omitted. The Kis and Kid residues that are perturbed due to Kid-Kis interactions in the NMR titration experiments are colored yellow and blue for the two Kis monomers, respectively, and red for the Kid dimer. The color coding is identical to that used in Figure 5, but no gradients are used here. The Kid-Kis interaction sites 1-4 defined in this article are indicated in the same color, except the numbers of the perturbed residues of the lateral Kid monomers (indicated by ${ }^{\#}$ in the text) that are colored purple. The MazE interaction sites of Kid are indicated with green numbers above the Kid-Kis interaction sites (light green is used for the numbers of the perturbed residues of the lateral Kid monomers). Residues for which a perturbation is observed that could not be attributed to one of the defined interaction sites are marked with an $\mathrm{x}$. For comparison to the MazF-MazE complex, the interacting residues defined by Burley and coworkers ${ }^{30}$ are colored grey. The numbers of the MazF and MazE interaction sites are shown in black, except for the lateral MazF monomers and the second MazE monomer, which are shown in grey.

704 during the Kid titration. All spectra were processed with the NMRPIPE software package ${ }^{35}$ and analyzed with NMRView. ${ }^{36}$ The normalized decrease in peak intensities of the original Kid resonances upon Kis binding was determined by averaging the differences in peak intensities between the ${ }^{1} \mathrm{H}-{ }^{15} \mathrm{~N}$ HSQC spectrum of pure Kid and the ${ }^{1} \mathrm{H}-{ }^{15} \mathrm{~N}$ HSQC spectra recorded after each addition of Kis up to a Kis:Kid ratio of 1:1, divided by the intensity difference of residue V36. Chemical shift perturbations in the ${ }^{1} \mathrm{H}$ and ${ }^{15} \mathrm{~N}$ dimensions were combined to a weighed composite shift perturbation $\Delta=\sqrt{ }\left((\delta \mathrm{H})^{2}+(\delta \mathrm{N} / 6.51)^{2}\right) .{ }^{38} \mathrm{~A}$ cut-off of 1.1 times the average intensity decrease or chemical shift perturbation was used to define the residues that were significantly perturbed because of the addition of the partner protein.

\section{Modelling of the Kid-Kis Complex}

A model of the $\mathrm{Kid}_{2}-\mathrm{Kis}_{2}-\mathrm{Kid}_{2}$ heterohexamer was obtained with the software Modeller6v2. ${ }^{39}$ The crystal structure of the $\mathrm{MazF}_{2}-\mathrm{MazE}_{2}-\mathrm{MazF}_{2}$ complex (PDB:1UB4) ${ }^{30}$ was used as template, with the Kid/MazF and Kis/MazE sequences aligned as shown in Figure 1. One hundred structures were calculated and the solution with the lowest Modeller6v2 energy score was used for the interpreta- 
tion of our NMR titration data. Ramachandran analysis was performed with the program Procheck. ${ }^{40}$

\section{Native Macromolecular Mass Spectrometry Experiments}

Samples were introduced into a nanoflow electrospray ionization orthogonal time-of-flight mass spectrometer (Micromass LCT, Waters, Manchester, UK) modified for high mass operation and operating in positive ion mode. Borosilicate glass capillaries (Kwik-Fil, World Precision Instruments, Sarasota, FL) were used on a P-97 puller (Sutter Instrument Co., Novato, CA) to prepare the nanoflow electrospray capillaries with an orifice of about $5 \mu \mathrm{m}$. The capillaries were subsequently coated with a thin gold layer ( $\sim 500 \AA$ ) by using an Edwards ScanCoat Six Pirani 501 sputter coater (Edwards High Vacuum International, Crawley, UK). To generate intact ions in vacuo from protein complexes in solution, the ions were cooled by increasing the pressure in the first vacuum chamber of the mass spectrometer. ${ }^{41,42}$ The source pressure was increased to 7 mbar by reducing the pumping capacity of the rotary pump by closing the speedi-valve. In addition, nanoflow electrospray voltages were optimized for transmission of intact protein complexes using a capillary voltage of $1300 \mathrm{~V}$ and a cone voltage of $50 \mathrm{~V}$, and the capillary temperature was adjusted to $80^{\circ} \mathrm{C}$. All spectra were scanned in the range of 400 to $8000 \mathrm{~m} / \mathrm{z}$ at a $2 \mathrm{~s}$ scan rate for $2 \mathrm{~min}$. All spectra were mass calibrated by using an aqueous solution of cesium iodide $(5 \mathrm{mg} / \mathrm{mL})$. The mass spectra were analyzed using MassLynx version 4.0.

\section{RESULTS AND DISCUSSION}

\section{Secondary Structures of Kis and Kid}

The structure of the Kis antitoxin is unknown. Therefore, NMR assignments of ${ }^{13} \mathrm{C} /{ }^{15} \mathrm{~N}$-labeled protein were obtained for the Kis backbone resonances. $2 \mathrm{D}{ }^{1} \mathrm{H}^{-15} \mathrm{~N}$ HSQC and ${ }^{1} \mathrm{H}^{-13} \mathrm{C}$ HSQC experiments and 3D HNCA, $\mathrm{HN}(\mathrm{CO}) \mathrm{CA}, \mathrm{HNCACB}, \mathrm{CBA}(\mathrm{CO}) \mathrm{NH}, \mathrm{HNCO}, \mathrm{HA}(\mathrm{CA}) \mathrm{NH}$, and $\mathrm{HBA}(\mathrm{CO}) \mathrm{NH}$ experiments were recorded to achieve a high level of completeness of the backbone assignments: ${ }^{1} \mathrm{HN} 100 \%,{ }^{1} \mathrm{H} \alpha$ 95\%, ${ }^{1} \mathrm{H} \beta$ 93\%, ${ }^{15} \mathrm{~N} 100 \%,{ }^{13} \mathrm{C} \alpha 99 \%,{ }^{13} \mathrm{C} \beta$ $99 \%$, and ${ }^{13} \mathrm{CO} 87 \%$. With the program TALOS, ${ }^{37}$ the dihedral angles of the protein were predicted based on the $\mathrm{N}$, $\mathrm{C} \alpha$, and $\mathrm{C} \beta$ chemical shifts and those values were converted into the secondary structure of Kis in solution, as shown in Figure 1(a). The N-terminal part of Kis is highly structured. It contains four $\beta$-strands, one $\alpha$-helix, and a helical turn: $\beta 1-\beta 4$ comprise residues $4-11,15-20,35-40$, and $43-50$, respectively, and $\alpha 1$ is formed by residues $21-$ 26. The C-terminal region of Kis is mostly unstructured and contains just one $\alpha$-helix and a helical turn: $\alpha 2$ comprises residues 56-59. Figure 1(a) displays also the amino acid sequence and secondary structure elements of MazE, the chromosomal homologue of Kis, determined by X-ray spectroscopy in complex with MazF (PDB: 1UB4). ${ }^{30}$ The structures of the two antitoxins clearly show a high level of similarity. The differences are that Kis contains a longer $\beta 4$-strand and a shorter $\alpha 2$-helix than MazE.

Although the crystal structure of Kid has been solved, NMR backbone assignments of ${ }^{13} \mathrm{C} /{ }^{15} \mathrm{~N}$-labeled Kid were obtained to determine the secondary structure elements of Kid in solution and to allow a detailed NMR study of the interactions between Kid and Kis. The same procedure was followed as described for Kis, and also for Kid a high level of completeness of the backbone assignments was achieved: ${ }^{1} \mathrm{HN} 100 \%,{ }^{1} \mathrm{H} \alpha 99 \%,{ }^{1} \mathrm{H} \beta 35 \%,{ }^{15} \mathrm{~N} 100 \%,{ }^{13} \mathrm{C} \alpha$ $100 \%,{ }^{13} \mathrm{C} \beta 100 \%$, and ${ }^{13} \mathrm{CO} 91 \%$. Analysis of the chemical shifts with the program TALOS resulted in the secondary structure elements of Kid shown in Figure 1(b), comprising six $\beta$-strands and three $\alpha$-helices. For comparison, the secondary structure of Kid inferred from the Kid crystal structure (PDB: $1 \mathrm{M} 1 \mathrm{~F})^{31}$ is also shown in Figure 1(b). Only a few differences are observed: our structure contains a slightly shifted $\beta 6$-strand, lacks the $\beta 7$-strand, and has a slightly longer $\alpha 3$-helix. Clearly, a close match exists between the structural elements of Kid obtained by X-ray and NMR spectroscopy, indicating a high structural similarity between the crystal and solution states of Kid. Therefore, the 3D crystal structure of Kid can be used for the interpretation of our data concerning Kid in solution. Finally, Figure 1(b) also presents the amino acid sequence and secondary structure elements of MazF, the chromosomal homologue of Kid, inferred from the MazF-MazE crystal structure (PDB: 1UB4). ${ }^{30}$ Using our NMR-based TALOS predictions, we show that considerable structural similarity exists between Kid in solution and the crystal structure of MazF, corroborating the high level of similarity reported for the crystal structures of Kid and MazF (rmsd $=2.2 \AA, 98$ equivalent $\alpha$-carbon pairs, $25 \%$ sequence identity). ${ }^{30}$

\section{Kid and Kis Form Multiple Complexes}

The crystal structure of the MazF-MazE complex shows a hexameric arrangement where one MazE dimer binds two MazF dimers. For the homologous CcdB-CcdA system in solution, various aggregation states were found. ${ }^{43}$ Therefore, we set up an analysis of the Kid-Kis complexes formed at different Kid:Kis ratios using native macromolecular mass spectrometry. ${ }^{32,33}$ An overview of the results is presented in Table I. Figure 2(a) displays a native mass spectrum of free Kid in aqueous $100 \mathrm{~m} M$ ammonium acetate, $\mathrm{pH}$ 5.8. The spectrum clearly shows a high abundant ion series around mass-to-charge $(\mathrm{m} / \mathrm{z}) 2700$ and a low abundant series around $m / z 1900$. Mass determination of the major ion series revealed a mass of $24,078 \pm 3 \mathrm{Da}$, which is in agreement with the mass of dimeric Kid as calculated from the primary sequence $(24,075 \mathrm{Da})$. The low abundant ion series was identified to be monomeric Kid with a determined mass of $12,037 \pm 1 \mathrm{Da}$. The observation that Kid mainly exists as a dimer agrees well with the crystal structure of the protein ${ }^{31}$ and previously reported ultracentrifugation data, ${ }^{15}$ and shows that native mass spectrometry is able to retain the noncovalent interactions between the protein subunits. The same experiment for 
TABLE I. Kid-Kis Complexes Observed at Different Molar Ratios of Kid and Kis by Nanoflow Electrospray Ionization Mass Spectrometry

\begin{tabular}{|c|c|c|c|c|c|c|c|c|}
\hline \multirow[b]{2}{*}{$\begin{array}{l}\text { Kid:Kis } \\
\text { ratio }\end{array}$} & \multicolumn{8}{|c|}{ Mass (Da) } \\
\hline & $\mathrm{Kid}_{2}$ & $\mathrm{Kis}^{\mathrm{a}}$ & $\mathrm{Kid}_{2} \mathrm{Kis}$ & $\mathrm{Kid}_{2} \mathrm{Kis}_{2}$ & $\mathrm{Kid}_{2} \mathrm{Kis}_{2} \mathrm{Kid}_{2}$ & $\mathrm{Kis}_{2} \mathrm{Kid}_{2} \mathrm{Kis}_{2}$ & $\begin{array}{l}\mathrm{Kid}_{2} \mathrm{Kis}_{2^{-}} \\
\mathrm{Kid}_{2} \mathrm{Kis}_{2}\end{array}$ & $\begin{array}{c}\mathrm{Kis}_{2} \mathrm{Kid}_{2} \mathrm{Kis}_{2} \\
\mathrm{Kid}_{2} \mathrm{Kis}_{2} \\
\end{array}$ \\
\hline $4: 1$ & $24,078 \pm 3^{\mathrm{b}}$ & $-^{\mathrm{c}}$ & $33,820 \pm 25$ & - & $67,719 \pm 10$ & - & - & - \\
\hline $2: 1$ & - & - & $33,835 \pm 25$ & - & $67,716 \pm 10$ & - & - & - \\
\hline $1: 1$ & - & - & $33,841 \pm 25$ & $43,450 \pm 5$ & $67,722 \pm 10$ & - & $87,120 \pm 15$ & - \\
\hline $1: 2$ & - & $\begin{array}{r}9,687 \pm 2 \\
19,373 \pm 4\end{array}$ & - & $43,455 \pm 5$ & - & $62,874 \pm 24$ & $87,109 \pm 15$ & $106,377 \pm 41$ \\
\hline
\end{tabular}

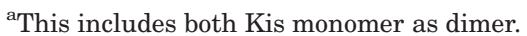

${ }^{\mathrm{b}}$ The standard deviation is calculated from at least three independent measurements.

c_ indicates not observed.
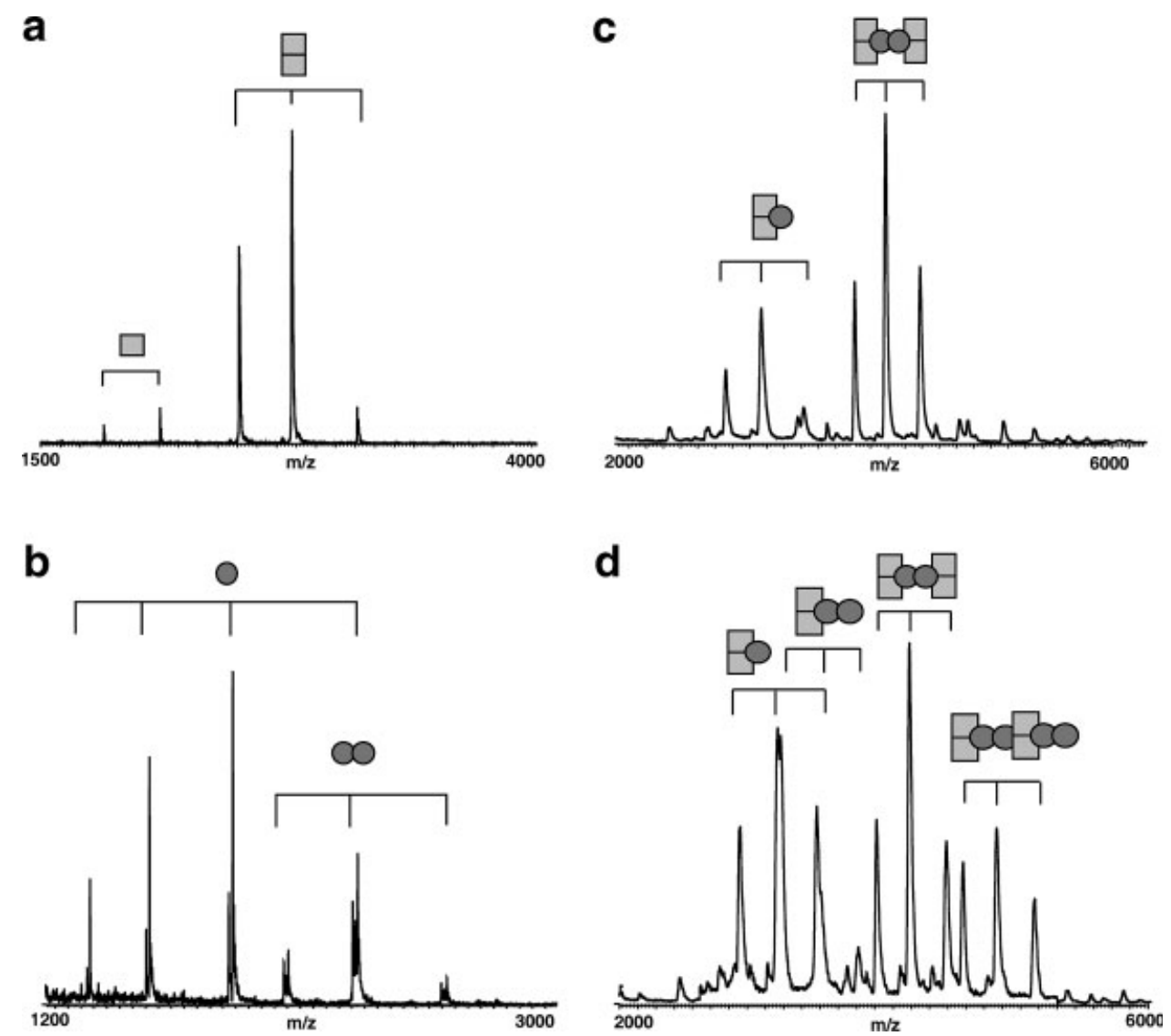

Fig. 2. Native mass spectrometric analyses of the formation of Kid-Kis complexes. Figures (a) and (b) show the mass spectra of Kid and Kis, respectively, at $5 \mu \mathrm{M}$. Monomers and dimers are indicated by single and double squares (Kid) or circles (Kis). See Results and Discussion section for details. Figures (c) and (d) show the mass spectra obtained at a Kid:Kis ratio of $2: 1$ and $1: 1$, respectively, at $15 \mu M$ of Kid. Combined squares and circles indicate the $\mathrm{Kid}_{2}-\mathrm{Kis}$ trimer, $\mathrm{Kid}_{2}-\mathrm{Kis}_{2}$ tetramer, $\mathrm{Kid}_{2}-\mathrm{Kis}_{2}-\mathrm{Kid}_{2}$ hexamer and $\mathrm{Kid}_{2}-\mathrm{Kis}_{2}-$ $\mathrm{Kid}_{2}-\mathrm{Kis}_{2}$ octamer. Measured molecular masses of the complexes are indicated in Table I.

free Kis yielded a mass spectrum with two ions series of similar abundance [Fig. 2(b)]. Mass determination of the two species revealed molecular masses of $9687 \pm 2 \mathrm{Da}$ and $19,373 \pm 4 \mathrm{Da}$, which could be assigned to monomeric and dimeric Kis, respectively. The ratio between these two forms varied depending on the Kis concentration, indicating that the equilibrium constant is in the low micromolar range. A similar monomer-dimer equilibrium was recently reported for MazE. ${ }^{44}$ The determined mass of monomeric Kis is in close agreement with the mass as calculated from the primary sequence of ${ }^{15} \mathrm{~N}$-labeled Kis attached to $\beta$-mercaptoethanol and sodium (9688.9 Da). The adduct formation with $\beta$-mercaptoethanol is quite likely to be an artefact of the purification. When Kis was electrosprayed from $50 \%(\mathrm{v} / \mathrm{v})$ acetonitrile (data not shown), exclusively unfolded Kis monomers were observed indicating that 
the Kis dimer interaction is noncovalent as shown in Figure 2(b).

Upon mixing different amounts of Kis to Kid, multiple oligomeric species were detected. Similar results were obtained for the "reversed" experiments in which different amounts of Kid were added to a fixed amount of Kis. At a Kid:Kis ratio of 4:1, the mass spectrum shows three ion series corresponding to species with molecular masses of $24,078 \pm 3,33820 \pm 25$, and $67,719 \pm 10 \mathrm{Da}$, which can be unambiguously identified as free Kid dimer, $\mathrm{Kid}_{2}-\mathrm{Kis}$ trimer and $\mathrm{Kid}_{2}-\mathrm{Kis}_{2}-\mathrm{Kid}_{2}$ hexamer, respectively. The observed composition of the two Kid-Kis complexes is fully compatible with the oligomerization behavior of the two separate proteins, i.e. in their free forms Kid is mainly in its dimeric conformation, whereas Kis is in equilibrium between its monomeric and dimeric conformation. At a Kid:Kis ratio of 2:1, no free proteins were detected and an increase of the intensity of the peaks assigned to the heterotrimer and heterohexamer was observed [Fig. 2(c)]. This indicates a high affinity between Kid and Kis, in agreement with the high concentration of guanidinium chloride $(5 M)$ needed to separate the complex of the two proteins. ${ }^{14}$ The relative intensity of signals attributed to trimer and hexamer changed upon sample dilution; lowering the protein concentration 4-fold resulted in a higher amount of trimer. This suggests equilibrium between trimer and hexamer mediated by Kis monomer-monomer interactions. Spectra obtained at a Kid:Kis ratio of 1:1 show several oligomeric species [Fig. 2(d)], mainly $\mathrm{Kid}_{2}-$ Kis trimer $(33,841 \pm 25 \mathrm{Da}), \mathrm{Kid}_{2}-\mathrm{Kis}_{2}$ tetramer $(43,450$ $\pm 5 \mathrm{Da}), \mathrm{Kid}_{2}-\mathrm{Kis}_{2}-\mathrm{Kid}_{2}$ hexamer $(67,722 \pm 10 \mathrm{Da})$, and $\mathrm{Kid}_{2}-\mathrm{Kis}_{2}-\mathrm{Kid}_{2}-\mathrm{Kis}_{2}$ octamer $(87,120 \pm 15 \mathrm{Da})$. Upon a further increase of the Kis concentration up to a Kid:Kis ratio of 1:2 even higher mass oligomers were observed. Similar amounts of $\mathrm{Kid}_{2}-\mathrm{Kis}_{2}$ tetramer (43,455 $\left.\pm 5 \mathrm{Da}\right)$, $\mathrm{Kis}_{2}-\mathrm{Kid}_{2}-\mathrm{Kis}_{2}$ hexamer $(62,874 \pm 24.2 \mathrm{Da}), \mathrm{Kis}_{2}-\mathrm{Kid}_{2}-$ $\mathrm{Kis}_{2}-\mathrm{Kid}_{2}$ octamer $(87,109 \pm 15 \mathrm{Da})$, and $\mathrm{Kis}_{2}-\mathrm{Kid}_{2}-\mathrm{Kis}_{2}-$ $\mathrm{Kid}_{2}-\mathrm{Kis}_{2}$ decamer $(106,377 \pm 41 \mathrm{Da})$ were detected. Our mass spectrometry data thus clearly demonstrate a correlation between the excess of Kis and the formation of multimeric, high molecular mass Kid-Kis complexes (Table I). We also clearly detect a predominance of $\mathrm{Kis}_{2}$ subunits in all complexes formed upon increasing the Kis concentration, i.e. the $\mathrm{Kis}_{2}-\mathrm{Kid}_{2}-\mathrm{Kis}_{2}$ and $\mathrm{Kis}_{2}-\mathrm{Kid}_{2}-\mathrm{Kis}_{2}-\mathrm{Kid}_{2}-$ $\mathrm{Ki}_{2}$ complexes become more abundant and the $\mathrm{Kid}_{2}-$ $\mathrm{Kis}_{2}-\mathrm{Kid}_{2}$ complex becomes less abundant. On the other hand, the $\mathrm{Kid}_{2}-\mathrm{Kis}_{2}-\mathrm{Kid}_{2}$ hexamer is the most abundant species in all situations where Kid is in excess of Kis.

The interactions between the antitoxin $\mathrm{CcdA}$ and the toxin $\mathrm{CcdB}$, which is structurally related to Kid, $31,45,46$ display a similar complex behavior. ${ }^{43}$ Like observed for Kid and Kis, a CcdB-CcdA heterohexamer was obtained after mixing $\mathrm{CcdB}$ and $\mathrm{CcdA}$ at a 2:1 molar ratio. A model of the mixture of complexes obtained at a 1:1 molar ratio was presented. For Kid and Kis, we could identify the complexes formed at equimolar toxin:antitoxin concentrations as $\mathrm{Kid}_{2}-\mathrm{Kis}, \mathrm{Kid}_{2}-\mathrm{Kis}_{2}, \mathrm{Kid}_{2}-\mathrm{Kis}_{2}-\mathrm{Kid}_{2}$, and $\mathrm{Kid}_{2}-$ $\mathrm{Kis}_{2}-\mathrm{Kid}_{2}-\mathrm{Kis}_{2}$. For the CcdA-CcdB system, however, a heterotrimer was not considered in the model. a

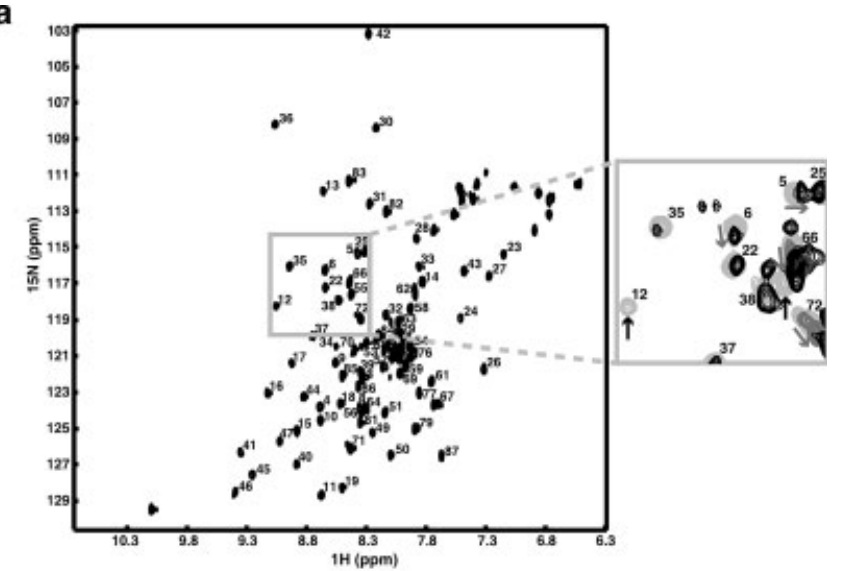

b

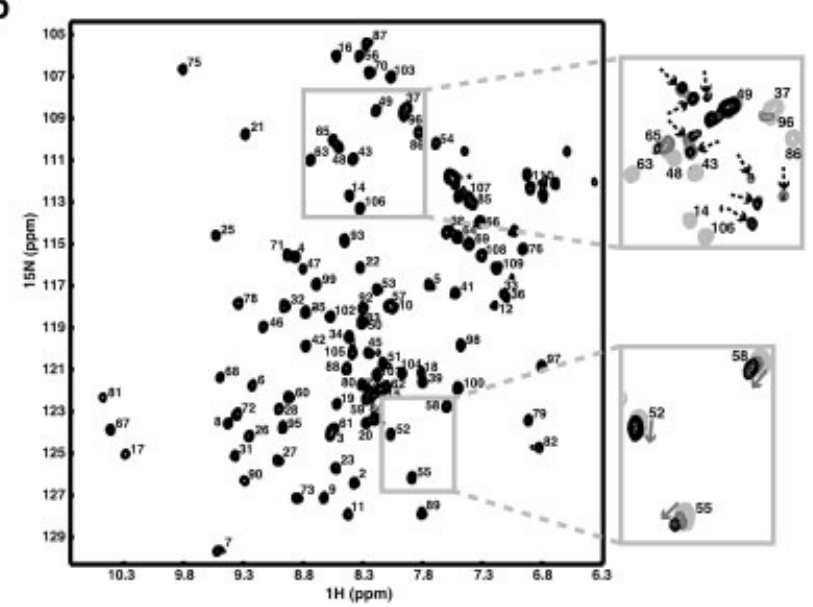

Fig. 3. ${ }^{1} \mathrm{H}^{-15} \mathrm{~N}$ HSQC spectra of Kis (a) and Kid (b). The enlargements show overlays of spectra of ${ }^{15} \mathrm{~N}$-labeled protein recorded during NMR titration experiments with an unlabeled partner protein. In Figure (a), the enlargement shows the spectra recorded of pure ${ }^{15} \mathrm{~N}$-labeled Kis (light grey) and with Kid:Kis ratios of 2:3 (dark grey) and 3:2 (black). In Figure (b), the spectra recorded of pure ${ }^{15} \mathrm{~N}$-labeled Kid (light grey) and at Kis:Kid ratios of 1:1 (dark grey) and 2:1 (black) are shown in the upper enlargement, and at MazE:Kid ratios of 1:2 (dark grey) and 7:2 (black) in the lower enlargement. Black arrows indicate amide peaks disappearing upon addition of unlabeled protein, grey arrows the directions of the chemical shift perturbations, and dashed black arrows amide signals appearing at Kid:Kis ratios approaching 1:1. The residue numbering for the backbone amide resonances is indicated.

\section{Residues Involved in the Kid-Kis Interactions}

The residues of Kid and Kis involved in the formation of Kid-Kis complexes were identified via two titration experiments followed by ${ }^{1} \mathrm{H}-{ }^{15} \mathrm{~N}$ HSQC spectra (Figure 3). In the first titration experiment, unlabeled Kid was gradually added to a sample of ${ }^{15} \mathrm{~N}$-labeled Kis to a final molar ratio of Kid: ${ }^{15} \mathrm{~N}$-Kis of 3:1 to identify the residues of Kis involved in Kid binding. Under these conditions, predominantly the $\mathrm{Kid}_{2}-\mathrm{Kis}_{2}-\mathrm{Kid}_{2}$ hexamer will be present. The $\mathrm{Kid}_{2}-\mathrm{Kis}$ trimer is not likely to exist, since the concentration of Kis is much higher than during the mass spectrometry experiments and therefore the Kis equilibrium will be shifted toward the dimeric form. The measured ${ }^{1} \mathrm{H}_{-}{ }^{15} \mathrm{~N}$ HSQC spectra [Fig. 3(a)] show Kis resonances in fast, slow, and intermediate exchange, of which the chemi- 
a

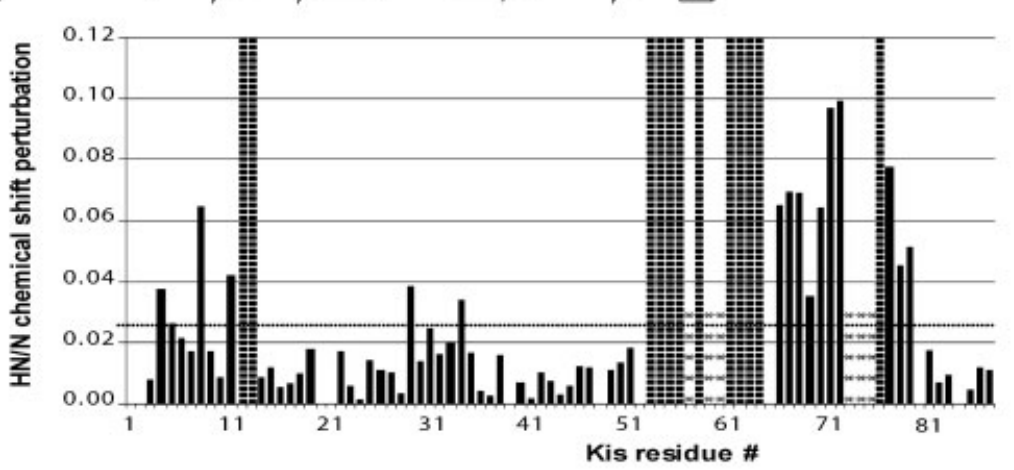

b
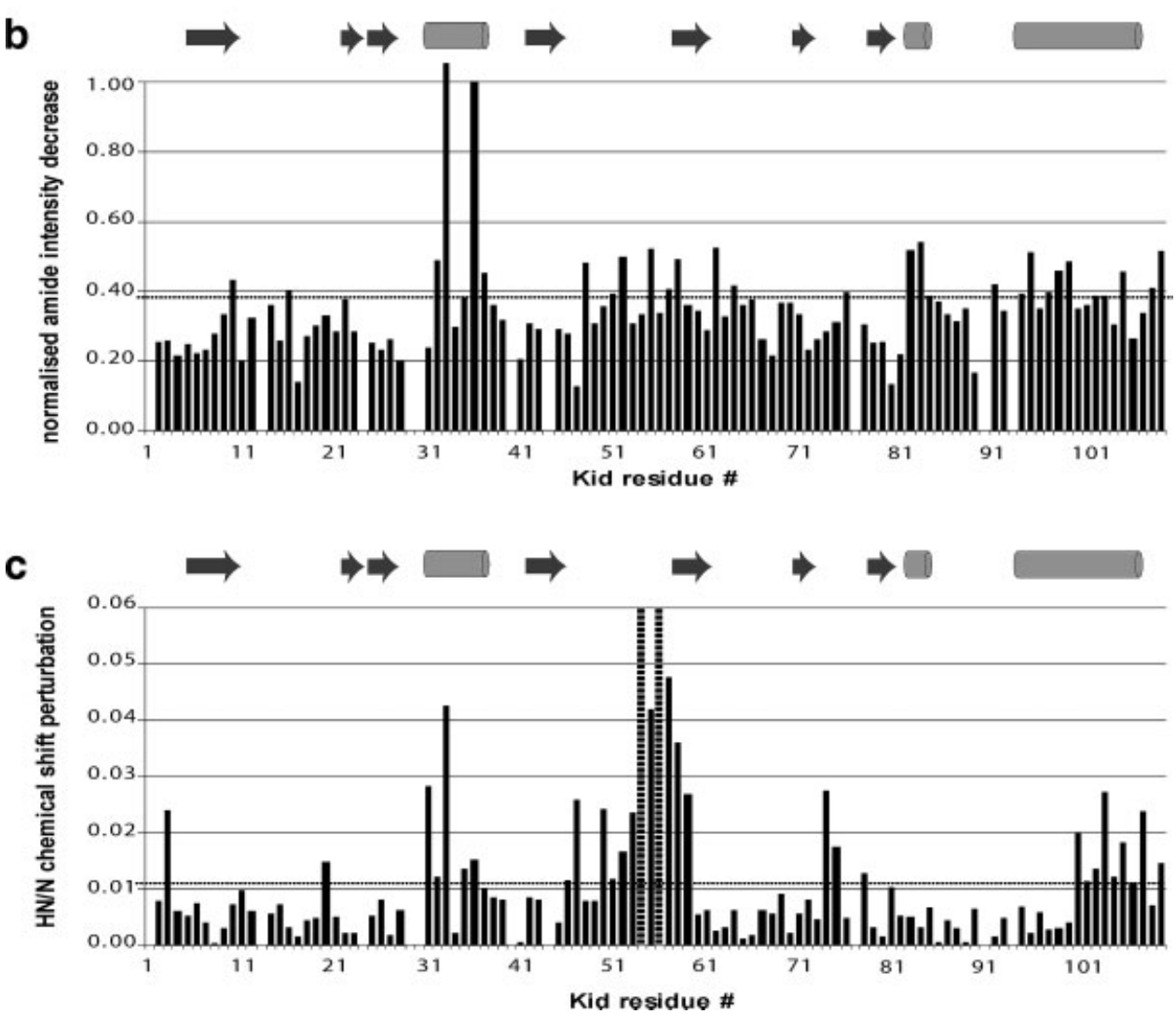

Fig. 4. Kis and Kid residues involved in binding their partner protein(s). (a) Chemical shift perturbation diagram (ppm) for Kis residues upon addition of Kid up to a Kid:Kis ratio of 3:2. (b) Normalized decrease in peak intensities of the original Kid resonances upon addition of Kis up to a Kis:Kid ratio of 1:1 (see Materials and Methods section for details). (c) Chemical shift perturbation diagram (ppm) for Kid residues upon addition of MazE up to a MazE:Kid ratio of 4:1. In Figures (a) and (c), vertical dashed lines indicate disappearing residues in slow/intermediate exchange, while stars mark Kis residues A57, L59, L60, E73, R74, and E75 of which the amide signals could not be identified in the spectrum of the Kid-Kis complex. The resonances of Kid T29 and E91 and Kis I39 and Q84 are excluded because of severe overlap and prolines are not observed (residues 20, 21, 48, 52, 65, and 80 in Kis and residues 13, 24, 30, 40, 44, 77, and 94 in Kid). In all diagrams, the cut-off of 1.1 times the average perturbation or intensity decrease is indicated with a horizontal dashed line. The secondary structure elements of the proteins are indicated.

cal shift perturbations are presented in Figure 4(a). The amide signals of G12, G13, Q53-L56, E58, A61-V64, and W76 are in slow or intermediate exchange, indicating that those residues maintain tight interactions with Kid, or alternatively, experience a major change in their environ- ment because of indirect effects of Kid binding. The amide signals of H4, T5, L8, V11, L29, E34, R50, R51, N66-E72, and L77 are in fast exchange and therefore those residues interact weakly with the toxin or experience a limited environmental change. The amide signals of A57, L59, 
L60, E73, R74, and E75 could not be identified in the ${ }^{1} \mathrm{H}-{ }^{15} \mathrm{~N}$ HSQC spectrum of the Kid-Kis complex. They might either have disappeared or shifted to a crowded region of the spectrum and therefore it is not clear whether their resonances are in slow/intermediate or fast exchange. Figure 4(a) shows that most perturbations, including nearly all extensive ones, are observed for residues R50-L77 in the C-terminal part of Kis, located both in the $\alpha$-helix and unstructured regions. This fits well with the functional data on the carboxy-terminal Kis region, i.e. that this part of the antitoxin is indispensible for Kid inhibition and autoregulation of parD transcription. ${ }^{19}$ The way in which Kis binds Kid appears to be similar to MazF-binding by MazE, as observed in the crystal structure of the MazF-MazE hexamer. ${ }^{30}$

In the second experiment, the Kid residues involved in Kis binding were determined by the gradual addition of unlabeled Kis to a ${ }^{15} \mathrm{~N}$-labeled Kid sample, up to a final molar ratio of Kis: ${ }^{15} \mathrm{~N}$-Kid of 4:1. The appearance of three resonances of ${ }^{15} \mathrm{~N}$-Kid at an early stage of the titration suggests the existence of a minor population of a relatively small Kid-Kis complex, possibly the $\mathrm{Kid}_{2}-\mathrm{Kis}_{2}$ tetramer as observed in the mass spectrometry experiments. At slightly higher ratios up to a Kis:Kid ratio of $1: 1$, the formation of the main Kid-Kis complex was indicated by several new resonances of ${ }^{15} \mathrm{~N}$-Kid [Fig. 3(b)]. According to the mass spectrometry results, this complex is the $\mathrm{Kid}_{2}-\mathrm{Kis}_{2}-\mathrm{Kid}_{2}$ hexamer, since Kid is present in excess of Kis at this stage of the experiment. The amide signals of Kid were mostly in an intermediate exchange state, as only part of the peaks expected for the complex was observed. Figure 4(b) shows the normalized decrease in peak intensities of the original resonances of ${ }^{15} \mathrm{~N}$-Kid upon binding of Kis. The general intensity decrease is caused by broadening of the peaks because of the higher molecular weight of the Kid-Kis complexes compared with the free Kid dimer. The Kid residues experiencing a significant additional intensity decrease (more than 1.1 times the average intensity decrease) are mapped on the crystal structure of Kid in Figure 5(a) (light to dark red represents a mild to strong effect). It involves residues that are located mainly at the Kid dimer interface and in the C-terminal helix, forming interaction sites that compare well to the MazE binding sites of MazF within the $\mathrm{MazF}_{2}-\mathrm{MazE}_{2}-\mathrm{MazF}_{2}$ crystal structure. ${ }^{30}$ The interaction surfaces denoted site 2, 3, and 4 by Burley and coworkers can be clearly identified for Kid, as will be described. A further increase of the amount of Kis up to Kis:Kid ratios of $2: 1$ and $4: 1$ caused a complete loss of all Kid peak intensities [Fig. 3(b)], in agreement with the formation of large $\mathrm{Kid}_{2}-\mathrm{Kis}_{2}-\mathrm{Kid}_{2}-\mathrm{Kis}_{2}$ and $\mathrm{Kis}_{2}-\mathrm{Kid}_{2}-\mathrm{Kis}_{2}-\mathrm{Kid}_{2}-\mathrm{Kis}_{2}$ aggregates as observed by mass spectrometry.

\section{$\mathbf{K i d}_{\mathbf{2}}-\mathbf{K i s}_{\mathbf{2}}-\mathbf{K i d}_{\mathbf{2}}$ Model}

We have demonstrated that the secondary structures of free Kid and Kis in solution show considerable similarity to those of MazF and MazE in the MazF-MazE complex determined by crystallography. In addition, mass spec- trometry has revealed that mainly a hexameric $\mathrm{Kid}_{2}-$ $\mathrm{Kis}_{2}-\mathrm{Kid}_{2}$ complex is formed in mixtures of the two proteins when Kid is present in excess of Kis, at higher Kis concentrations such as used in the NMR experiments. Furthermore, the NMR titrations have demonstrated that the Kid-Kis interaction sites show considerable similarity to the MazF-MazE interaction sites within the MazF-MazE heterohexamer. Therefore, we used the 3D crystal structure of the $\mathrm{MazF}_{2}-\mathrm{MazE}_{2}-\mathrm{MazF}_{2}$ complex to obtain a model of the $\mathrm{Kid}_{2}-\mathrm{Kis}_{2}-\mathrm{Kid}_{2}$ hexamer with the program Modeller6v2 $2^{39}$ and the sequence alignments presented in Figure 1. The solution with the lowest Modeller6v2 energy score was analyzed with Procheck ${ }^{40}$ and the following Ramachandran scores were obtained: $88.0 \%$ core, $11.0 \%$ allowed, $0.8 \%$ generously allowed, and $0.2 \%$ disallowed. This $\mathrm{Kid}_{2}-\mathrm{Kis}_{2}-\mathrm{Kid}_{2}$ model, shown in Figure $5(\mathrm{~b})$, is used for the interpretation of our data concerning Kid and Kis in solution. The Kid residues for which a significant additional intensity decrease is observed upon binding of Kis are mapped using the same color coding as in Figure 5(a). In addition, the Kis residues affected by Kid binding are colored yellow on one Kis monomer and blue on the other. A similar color coding is also used in Figure 1 to show the location of the interacting residues on the Kis and Kid sequences.

\section{Interaction Sites Within the Kid-Kis Hexamer}

The MazF-MazE interaction sites defined by Burley and coworkers ${ }^{30}$ are depicted in Figure 1. They are based on the MazE sequence and therefore easily translated to Kis [Fig. 1(a)]. First, Kid-Kis interaction sites 1, 2, and 3 will be described, since they involve the carboxy-terminal tail of the antitoxin. Site 4 that comprises interactions between Kid and the N-terminal part of Kis will be discussed later. In analogy with MazE, Kis interaction site 1 would involve residues A71-A79, site 2 residues L56S70, and site 3 residues P52-S55. For Kid, more care should be taken, because the definition of the interaction sites on MazF is not sequence-related, but inferred from the MazF-MazE interactions. Subtle differences between Kis and MazE might alter the toxin residues involved in antitoxin binding accordingly. The Kid interaction sites [Fig. 1(b)] are identified using the amide intensity perturbations shown in Figure 4(b) and the $\mathrm{Kid}_{2}-\mathrm{Ki}_{2}-\mathrm{Kid}_{2}$ model presented in Figure 5(b). Since both monomers of each Kid dimer are involved in Kis binding, " will be used to indicate residues of the lateral Kid monomers that maintain a smaller number of interactions with Kis than the medial monomers. In Figure 1(b), the numbers indicating what interaction site these residues belong to are colored purple.

\section{Interaction site 1}

The similarity of MazF-MazE and Kid-Kis interaction sites 1 is less obvious than the other three interaction sites, although this site in particular was suggested to exist in all TA systems related to MazF-MazE. Indeed, the additional intensity decrease of Q76 of Kid fits with 
a

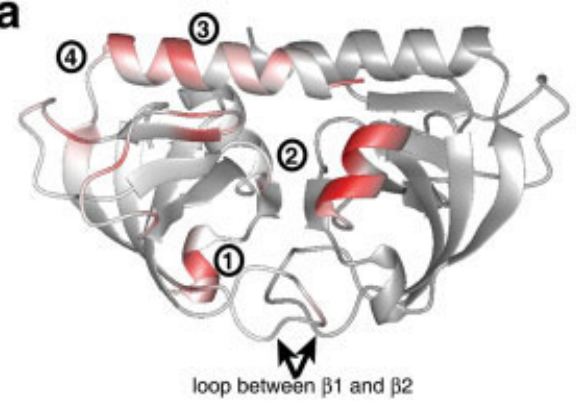

C

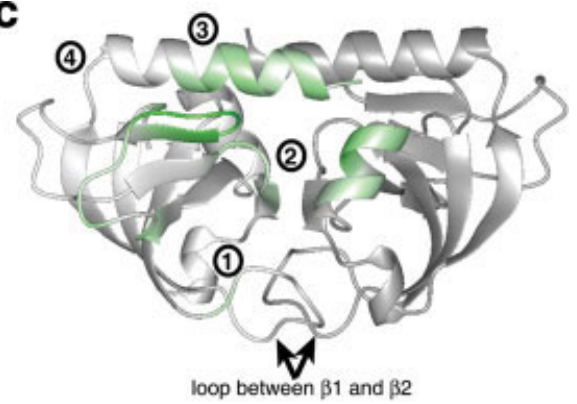

b

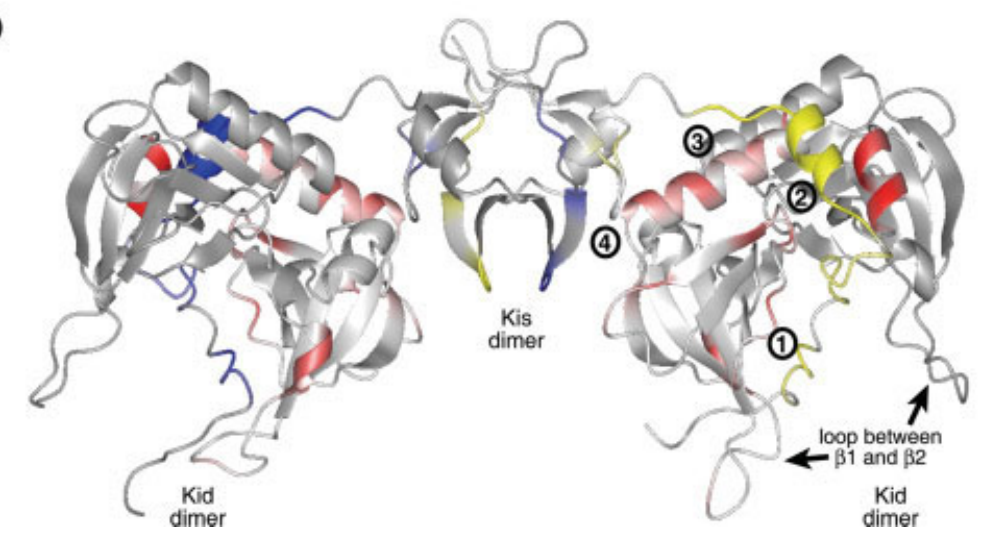

Fig. 5. Kid-Kis and Kid-MazE interactions mapped on ribbon representations of the dimeric Kid crystal structure (PDB: 1M1F) and the hexameric $\mathrm{Kid}_{2}-\mathrm{Kis}_{2}-\mathrm{Kid}_{2}$ model. (a) The Kid dimer is shown in two shades of grey with residues experiencing a significant additional intensity decrease (see Results and Discussion section for definition) upon the addition of Kis depicted in red. Light to dark red represents a mild to strong effect, ranging from normalized intensity decreases of $0.38-0.42,0.42-0.48,0.48-0.56$, and above 0.56 . Kid exists as a symmetric dimer and therefore two sets of originally identical residues can be distinguished. For clarity, however, only one of those sets is colored red on each dimer. (b) The Kid-Kis hexamer is shown in two shades of grey, with the medial Kid monomers in lighter grey than the lateral Kid monomers. Kid residues experiencing a significant additional intensity decrease (see text for definition) upon the addition of Kis are depicted in red. Light to dark red represents a mild to strong effect as described for Figure 1(a); only one set of residues is colored. Kis residues affected by Kid binding are shown in yellow and blue for the first and second monomer, respectively. Dark yellow/blue corresponds to slow/intermediate exchange [dashed lines in Figure $4(\mathrm{a})$ ] and light yellow/blue to composite ${ }^{1} \mathrm{H} /{ }^{15} \mathrm{~N}$ chemical shift perturbations larger than $0.026 \mathrm{ppm}$ (1.1 times the average). (c) The Kid dimer is shown in two shades of grey, with residues experiencing composite ${ }^{1} \mathrm{H} /{ }^{15} \mathrm{~N}$ chemical shift perturbations larger than 1.1 times the average upon MazE binding depicted in green. Light to dark green represents a mild to strong effect, ranging from perturbations of $0.011-0.020 \mathrm{ppm}$, $0.020-0.030$ ppm, 0.030 ppm and above, and peaks in intermediate exchange. Only one set of residues is colored. All figures were generated with the program MOLMOL version $2 \mathrm{~K} .1 .{ }^{47}$ The four interaction sites and the loop between $\beta$-strands 1 and 2, comprising residues S10-G21, are indicated.

the anchoring function described for Q77 of MazF, but no effect is measured for all but R85 of the conserved Kid residues V9, R23, V25, V42, P44, R78, I80, and R85. The hydrophobic pocket located in between those residues is quite likely to bind the side-chain of the conserved W76 of Kis (W73 of MazE), in analogy to MazF. However, since backbone amides are monitored in this experiment, a changed environment of the side-chains within this hydrophobic pocket is not likely to be observed. As mentioned and shown in Figure 4(a), significant chemical shift perturbations are observed for W76 and adjacent residues of Kis, corroborating this view. Kid residues S10, $\mathrm{K} 83$, and A84, located nearby this hydrophobic pocket, do show an additional intensity decrease. This is most likely due to a relocation of the loop between $\beta$-strands 1 and 2 (comprising residues S10-G21), induced by Kis binding, to a similar position as observed in the MazF-MazE com- plex. The position of this loop is the main difference between the crystal structure of free Kid and that of MazF bound to MazE, and its relocation upon antitoxin binding is thought to be a general phenomenon for this kind of TA systems. Alternatively, K83, K83", A84, and A84 ${ }^{\#}$ might interact with Kis directly. A relocation of the loop between $\beta 1$ and $\beta 2$ would also explain the additional intensity decrease of G16 of Kid.

\section{Interaction sites 2 and 3}

The hydrophobic interaction site 2 of Kid consists of residues A32 ${ }^{\#}, \mathrm{~F}_{3} 3^{\#}$, R35 ${ }^{\#}, \mathrm{~V} 36^{\#}$, and T37 ${ }^{\#}$ of the $\alpha$-helix located at the dimer interface together with A55, F57, and A58, and probably the nonvisible P30\#. The backbone of T37 ${ }^{\#}$ could be involved in an extra interaction with the side-chain of Kis residue N66, which is missing in MazE 
[Fig. 1(a)]. The additional intensity decrease that is observed for Kid residues L109 and T110 is likely an indirect effect of site 2 interactions, since no interactions are observed between those residues and Kis in the Kid-Kis model. Interaction site 3 of Kid contains residues E100, G103, R104, and S106 of the C-terminal $\alpha$-helix.

\section{Interaction site 4}

Figures 1(a) and 5(b) show that interaction site 4 of Kis comprises the N-terminal regions of both monomers of the intertwined Kis dimer. Amide chemical shift perturbations are reported for L29 and E34 of the Kis monomer that also maintains the interactions with Kid at sites 1 , 2 , and 3 . In addition, direct and indirect effects of site 4 interactions are observed for $\mathrm{H} 4, \mathrm{~T} 5, \mathrm{~L} 8, \mathrm{~V} 11, \mathrm{G} 12$, and G13 of the second Kis monomer [Figs. 1(a), 4(a), and 5(b)]. Interaction site 4 of Kid includes residues E95, T96, M98, N99, and possibly R92 of the C-terminal $\alpha$-helix [Fig. 1(b)]. The additional intensity decrease of Kid R92 might be caused by additional contacts with Kis or be an indirect effect of site 4 interactions.

Furthermore, additional intensity decreases are observed for residues G48, F51, A52, D62, and V64, all situated in loop regions and therefore prone to changes because of structural rearrangements in adjacent parts of the protein. However, residues G48, F51, and A52 might also form additional interactions with Kis, since they are located in a highly flexible loop of Kid (Kamphuis et al., unpublished results) that is slightly extended when compared with the same loop in MazF. Therefore, these three residues very likely are an extension of interaction site 1 . Finally, four stable Kid variants have been reported that are affected in their coregulatory activity. G4E, C74Y, and $\mathrm{E} 91 \mathrm{~K}$ mutations result in proteins unable to corepress the parD promoter but with preserved toxicity, ${ }^{17}$ while a P94L mutation abolishes both Kid activities. ${ }^{15}$ All these mutants can be accounted for by our results, since the residues involved are all located close to the Kid-Kis interaction sites.

\section{Why do TA Complexes Occur Predominantly as Hexamers?}

To understand the high tendency of the Kid and Kis proteins to form hexameric species (no free dimers, tetramers, octamers, etc. were observed with mass spectrometry at a Kid:Kis ratio of $2: 1$ ), it was evaluated why Kid-Kis complexes with a 1:1 stoichiometry would be unfavorable. First, the aforementioned CcdB-CcdA model indicates a preference for simultaneous binding of both carboxy-termini of the antitoxin dimer. ${ }^{43}$ Second, both our NMR results on Kid-Kis binding and the MazF-MazE crystal structure indicate that site 4 TA interactions prevent that both C-terminal tails of an antitoxin dimer bind to the same toxin dimer. Apparently, a linear complex of alternating toxin and antitoxin dimers is preferred for autoregulation of operon transcription, as has been suggested before. ${ }^{30,48}$ Third, the hexameric $\mathrm{MazF}_{2}-\mathrm{MazE}_{2}-\mathrm{MazF}_{2}$ was split, in silico, into two $\mathrm{MazF}_{2}-\mathrm{MazE}$ trimers of which the MazF dimers were subsequently superimposed to obtain an artificial MazE-MazF $\mathrm{M}_{2}-\mathrm{MazE}$ complex. Clearly, sterical hindrance was observed between side-chains of residues located in the $\alpha 1$-helix of the $\mathrm{N}$-terminal region, thus near interaction site 4, of the first MazE monomer, and side-chains of residues located in the $\alpha 2$-helix of the C-terminal part, thus within interaction site 2, of the second monomer. Apparently, this sterical hindrance is an efficient barrier to prevent the formation of extended TA complexes with a stoichiometry of $1: 1$ in situations where the toxin is present in excess of the antitoxin.

\section{MazE Binding by Kid Involves Part of Kis Binding Residues}

It has been shown in vivo that overproduction of MazE enhances cell growth of bacteria lacking the native Kis antitoxin, suggesting that MazE can substitute for Kis and a nontoxic Kid-MazE complex is formed. ${ }^{49}$ Therefore, we also investigated the Kid-MazE interactions by mass spectrometry and NMR spectroscopy. The native mass spectrum of free MazE [Fig. 6(a)] shows only one ion series. The determined mass of $19,005 \pm 3 \mathrm{Da}$ is in close agreement with that of dimeric MazE as calculated from the primary sequence shown in Figure 1, including the preceding GS residues. In contrast to the result obtained for Kis, no monomer is observed. Apparently, the MazE monomermonomer equilibrium is positioned far toward the dimeric form, which fits with the recently reported study on structural transitions of MazE. ${ }^{44}$ Mass spectra measured for mixtures of Kid and MazE with Kid:MazE ratios varying from $2: 1$ to $1: 6$ show mainly the charge states corresponding to free Kid and MazE proteins. In addition, a small amount of a heterotetramer $(43,226 \pm 16 \mathrm{Da})$ formed by Kid and MazE dimers is observed [Fig. 6(b)]. The high peak intensities of the free proteins indicate a rather low affinity between Kid and MazE. This corroborates the results from a NMR titration experiment followed by ${ }^{1} \mathrm{H}-{ }^{15} \mathrm{~N}$ HSQC spectra [Fig. 3(b)], where, upon the addition of unlabeled MazE up to a final molar ratio of MazE: ${ }^{15} \mathrm{~N}-$ Kid of 4:1, for a subset of the Kid resonances, chemical shift changes are observed in a fast NMR exchange regime.

The composite ${ }^{1} \mathrm{H} /{ }^{15} \mathrm{~N}$ chemical shift perturbations of the Kid resonances observed upon addition of MazE are shown in Figure 4(c) and mapped on the Kid structure in Figure 5(c) (light to dark green represents mild to strong perturbations). Kid interacts with MazE mainly via residues located at the dimer interface of the toxin. Sites 2 and 3, which are involved in Kid-Kis interactions, can clearly be identified for MazE binding as well [Figs. 1(b) and 5(c)]. Interaction site 2 comprises $\mathrm{A} 31^{\#}, \mathrm{~A} 32^{\#}, \mathrm{~F} 33^{\#}$, R35", V36 ${ }^{\#}$, R53, T54, A55, G56, F57, T107, and I108 (" denotes the lateral Kid monomer), while site 3 consists of V101, L102, G103, R104, L105, and S106. However, the extent in which the individual residues participate in antitoxin binding is rather different, as becomes clear by comparing the perturbations of the Kid amide resonances caused by Kis [Fig. 4(b)] and MazE [Fig. 4(c)]. Moreover, interaction site 4 that comprises the beginning of the 
a

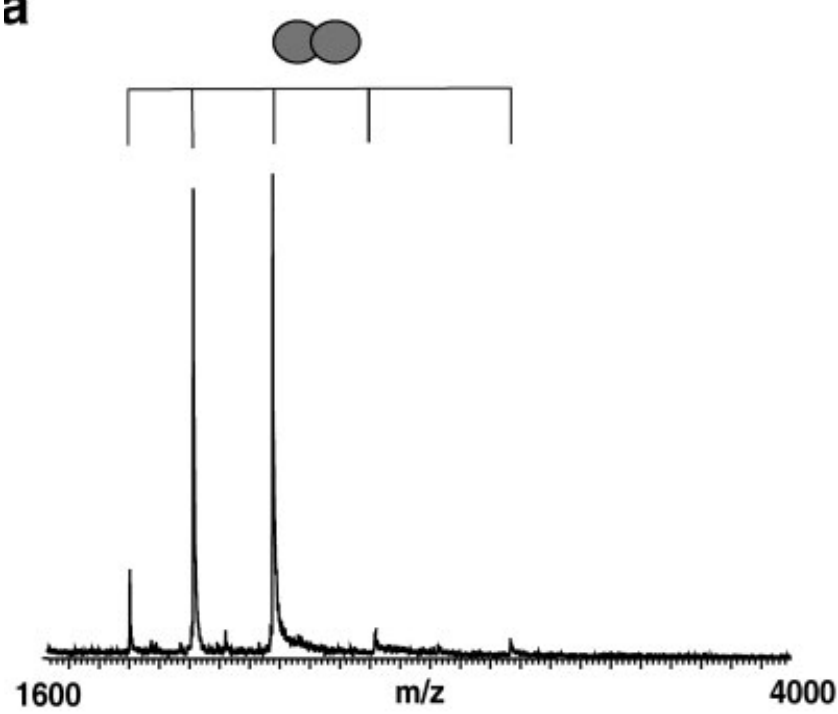

b

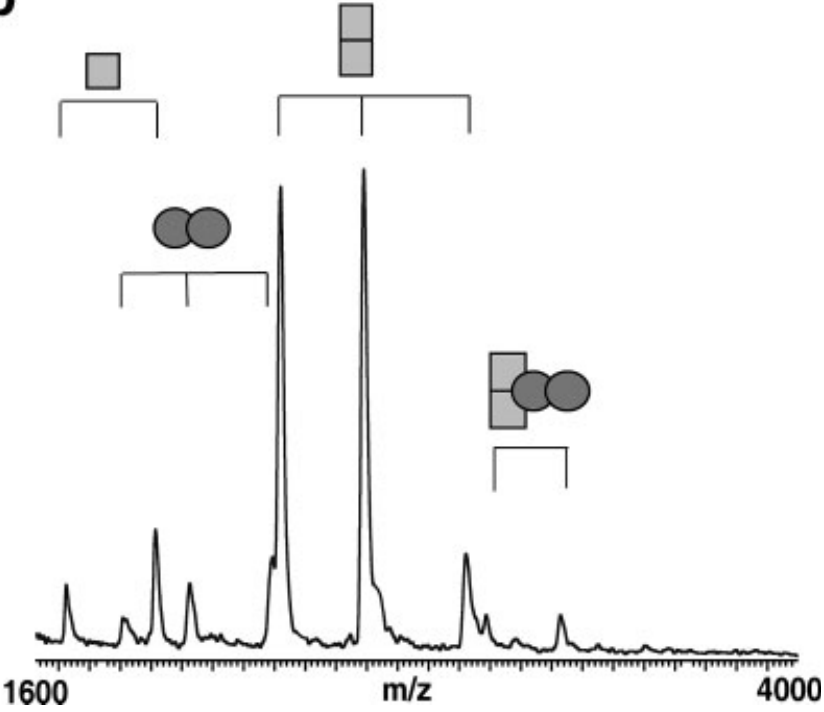

Fig. 6. Native mass spectrometric analysis of the formation of KidMazE complexes. Figure (a) shows the mass spectrum of MazE at 5 $\mu M$. See Results and Discussion section for details. Figure (b) shows the mass spectrum obtained at a Kid:MazE ratio of $2: 1$, at $15 \mu \mathrm{M}$ of Kid. Mainly free Kid and MazE are detected together with a low amount of the $\mathrm{Kid}_{2}-\mathrm{MazE}_{2}$ heterotetramer. Monomers and dimers are indicated by single and double squares (Kid) or circles (MazE).

C-terminal helix appears not to be involved in MazE binding at all. Finally, also no chemical shift perturbations are observed for interaction site 1 residues Q76, S10, K83, A84, and R85. Therefore, opening of the loop between $\beta$ strands 1 and 2 seems not likely to happen upon the addition of MazE. The perturbations of the resonances of $\mathrm{R} 3^{\# \text {, }}$ A58, V59, and T110 are probably indirect effects because of site 2 interactions. We have already suggested that the flexible loop of Kid comprising residues S47-A55 might be involved in additional interactions with Kis. Upon MazE binding, seven residues of this loop (S47, N50, F51, A52, R53, T54, and A55) display chemical shift perturbations. Therefore, it is very likely that the loop relocates to allow a maximum of interactions.

The different stoichiometry of the $\mathrm{Kid}_{2}-\mathrm{MazE}_{2}$ complexes compared with the Kid-Kis hexamer is probably the result of the much lower affinity of Kid for MazE than for Kis, as became obvious from the mass spectrometry data and the fast respectively slow/intermediate exchange modes observed in the NMR titration experiments. This fits with the result that the MazE interaction site of Kid is only part of the Kis interaction site.

\section{Functional Roles of the TA Interaction Sites}

Previously, noncytotoxic Kid variants have been reported that retained their ability to coregulate parD transcription. ${ }^{15,31}$ The respective mutations all involve residues that are important for, part of, or located near the recently revealed RNA binding sites of Kid, with the exception of P94S. From the results described in this article, it becomes clear that upon Kis binding, one of the RNA binding sites $^{28}$ will be partly occupied by the Cterminal antitoxin tail, corroborating the previously reported antidote function of this part of Kis. ${ }^{19}$ The associated "opening" of the loop between $\beta$-strands 1 and 2 will disrupt the second RNA binding pocket of Kid. ${ }^{28}$ Site 1 and $2 \mathrm{Kid}-\mathrm{Kis}$ interactions are thus responsible for neutralization of the Kid toxicity. The previously reported partial neutralization of Kid toxicity by MazE is likely to occur via the observed site 1 and 2 interactions as well. However, our data suggest that "opening" of the loops between $\beta$-strands 1 and 2 in Kid does not occur upon MazE binding. Therefore, neutralization of Kid toxicity by MazE probably occurs via another mechanism. We propose that both RNA binding sites of the Kid dimer are disrupted via site 1 and 2 interactions with the two tails of one MazE dimer. This is possible due to the lack of site 4 interactions, because the second MazE monomer is not forced into a fixed conformation and sterical hindrance between site 2 of the first MazE monomer and site 4 of the second monomer will neither be a problem.

Site 3 and $4 \mathrm{Kid}-\mathrm{Kis}$ interactions will enhance the TA affinity and therefore the inhibition of Kid action. In addition, site 4 interactions between Kid and the N-terminal part of Kis that is known to be involved in autoregulation ${ }^{19}$ are probably involved in a proper antitoxin-to-toxin orientation and in antitoxin monomer-monomer stabilization, which both seem to be important for effective transcriptional repression of the parD operon. Kid-MazE mediated repression of $\operatorname{parD}$ and $\operatorname{mazEF}$ transcription would be surprising, because, in addition to the very weak overall interactions between those proteins, no site 4 interactions are observed for Kid upon binding of MazE.

\section{Biological Function of the Different TA Complexes}

In a plasmid-containing cell, the Kis:Kid ratio is $\sim 4: 1$ (Bravo et al., unpublished results). We have shown that at these conditions (Kis:Kid 2:1) multimeric complexes 
are formed with a Kis:Kid ratio close to 1:1. Obviously, in this situation, the toxicity of Kid is neutralized and the system is autoregulated by the coordinate action of Kid and Kis to allow for sufficient expression of the antitoxin. The 1:1 stoichiometry of the Kid-Kis multimers might possibly account for more specific and stable proteinDNA interactions. When the plasmid is lost, the Kis:Kid ratio subsequently decreases. At these conditions, KidKis heterohexamers are formed to optimize the neutralization of Kid by Kis: a dimer of Kis can neutralize two dimers of Kid, and therefore the cell is still able to control the situation. Regulation is not required anymore as the plasmid is lost. Since Kid is more stable than its antitoxin, a progressive activation of the toxin will occur in time. At a Kid:Kis ratio of 4:1 and above, the Kid dimer coexists with the heterohexamer and cell growth should be affected increasingly.

Finally, our data on the Kid-MazE interactions indicate that upon loss of site 4 interactions, neutralization of the toxin by the heterologous antitoxin is far less efficient, likely because the orientation and stabilization of the antitoxin-toxin complexes is drastically affected. This, in combination with further differences in the regulatory region, could lead to clear independence and therefore coexistence of the homologous chromosomal and plasmid-encoded TA systems.

\section{REFERENCES}

1. Hayes F. Toxins-antitoxins: plasmid maintenance, programmed cell death, and cell cycle arrest. Science 2003;301:1496-1499.

2. Gerdes K, Christensen SK, Lobner-Olesen A. Prokaryotic toxinantitoxin stress response loci. Nat Rev Microbiol 2005;3:371-382.

3. Anantharaman V, Aravind L. New connections in the prokaryotic toxin-antitoxin network: relationship with the eukaryotic nonsense-mediated RNA decay system. Genome Biol 2003;4:R81.

4. Engelberg-Kulka H, Glaser G. Addiction modules and programmed cell death and antideath in bacterial cultures. Annu Rev Microbiol 1999;53:43-70.

5. Pedersen K, Christensen SK, Gerdes K. Rapid induction and reversal of a bacteriostatic condition by controlled expression of toxins and antitoxins. Mol Microbiol 2002;45:501-510.

6. Engelberg-Kulka H, Hazan R, Amitai S. mazEF: a chromosomal toxin-antitoxin module that triggers programmed cell death in bacteria. J Cell Sci 2005;118 (Part 19):4327-4332.

7. Engelberg-Kulka H, Sat B, Reches M, Amitai S, Hazan R. Bacterial programmed cell death systems as targets for antibiotics. Trends Microbiol 2004;12:66-71.

8. Pandey DP, Gerdes K. Toxin-antitoxin loci are highly abundant in free-living but lost from host-associated prokaryotes. Nucleic Acids Res 2005;33:966-976.

9. de la Cueva-Mendez G, Mills AD, Clay-Farrace L, Diaz-Orejas R, Laskey RA. Regulatable killing of eukaryotic cells by the prokaryotic proteins Kid and Kis. EMBO J 2003;22:246-251.

10. Picardeau M, Le Dantec C, Richard GF, Saint Girons I. The spirochetal chpK-chromosomal toxin-antitoxin locus induces growth inhibition of yeast and mycobacteria. FEMS Microbiol Lett 2003;229:277-281.

11. Yamamoto TA, Gerdes K, Tunnacliffe A. Bacterial toxin RelE induces apoptosis in human cells. FEBS Lett 2002;519:191-194.

12. Bravo A, de Torrontegui G, Diaz R. Identification of components of a new stability system of plasmid R1, ParD, that is close to the origin of replication of this plasmid. Mol Gen Genet 1987;210: 101-110.

13. Tsuchimoto S, Ohtsubo H, Ohtsubo E. Two genes, pemK and pemI, responsible for stable maintenance of resistance plasmid R100. J Bacteriol 1988;170:1461-1466.
14. Hargreaves D, Giraldo R, Santos-Sierra S, Boelens R, Rice DW, Diaz Orejas R, Rafferty JB. Crystallization and preliminary X-ray crystallographic studies on the parD-encoded protein Kid from Escherichia coli plasmid R1. Acta Crystallogr D Biol Crystallogr 2002;58 (Part 2):355-358.

15. Santos-Sierra S, Lemonnier M, Nunez B, Hargreaves D, Rafferty J, Giraldo R, Andreu JM, Diaz-Orejas R. Non-cytotoxic variants of the Kid protein that retain their auto-regulatory activity. Plasmid 2003;50:120-130.

16. Bravo A, Ortega S, de Torrontegui G, Diaz R. Killing of Escherichia coli cells modulated by components of the stability system ParD of plasmid R1. Mol Gen Genet 1988;215:146-151.

17. Lemonnier M, Santos-Sierra S, Pardo-Abarrio C, Diaz-Orejas R. Identification of residues of the kid toxin involved in autoregulation of the parD system. J Bacteriol 2004;186:240-243.

18. Ruiz-Echevarria MJ, Berzal-Herranz A, Gerdes K, Diaz-Orejas R. The kis and kid genes of the parD maintenance system of plasmid $\mathrm{R} 1$ form an operon that is autoregulated at the level of transcription by the co-ordinated action of the Kis and Kid proteins. Mol Microbiol 1991;5:2685-2693.

19. Santos-Sierra S, Pardo-Abarrio C, Giraldo R, Diaz-Orejas R. Genetic identification of two functional regions in the antitoxin of the parD killer system of plasmid R1. FEMS Microbiol Lett 2002; 206:115-119.

20. Munoz-Gomez AJ, Lemonnier M, Santos-Sierra S, Berzal-Herranz A, Diaz-Orejas R. RNase/anti-RNase activities of the bacterial parD toxin-antitoxin system. J Bacteriol 2005;187:3151-3157.

21. Munoz-Gomez AJ, Santos-Sierra S, Berzal-Herranz A, Lemonnier M, Diaz-Orejas R. Insights into the specificity of RNA cleavage by the Escherichia coli MazF toxin. FEBS Lett 2004;567:316320.

22. Zhang J, Zhang Y, Zhu L, Suzuki M, Inouye M. Interference of mRNA function by sequence-specific endoribonuclease PemK. J Biol Chem 2004;279:20678-20684.

23. Zhang Y, Zhang J, Hara H, Kato I, Inouye M. Insights into the mRNA cleavage mechanism by MazF, an mRNA interferase. J Biol Chem 2005;280:3143-3150.

24. Zhang Y, Zhang J, Hoeflich KP, Ikura M, Qing G, Inouye M. MazF cleaves cellular mRNAs specifically at ACA to block protein synthesis in Escherichia coli. Mol Cell 2003;12:913-923.

25. Zhang Y, Zhu L, Zhang J, Inouye M. Characterization of ChpBK, an mRNA interferase from Escherichia coli. J Biol Chem 2005;280: 26080-26088.

26. Christensen SK, Pedersen K, Hansen FG, Gerdes K. Toxin-antitoxin loci as stress-response-elements: ChpAK/MazF and ChpBK cleave translated RNAs and are counteracted by tmRNA. J Mol Biol 2003;332:809-819.

27. Pimentel B, Madine MA, de la Cueva-Mendez G. Kid cleaves specific mRNAs at UUACU sites to rescue the copy number of plasmid R1. EMBO J 2005;19:3459-3469.

28. Kamphuis MB, Bonvin AMJJ, Monti MC, Lemonnier M, MuñozGómez A, van den Heuvel RHH, Díaz-Orejas R, Boelens R. Model for RNA binding and the catalytic site of the RNase Kid of the bacterial parD toxin-antitoxin system. J Mol Biol 2006;357:115-126.

29. Loris R, Marianovsky I, Lah J, Laeremans T, Engelberg-Kulka H, Glaser G, Muyldermans S, Wyns L. Crystal structure of the intrinsically flexible addiction antidote MazE. J Biol Chem 2003; 278:28252-28257.

30. Kamada K, Hanaoka F, Burley SK. Crystal structure of the MazE/MazF complex: molecular bases of antidote-toxin recognition. Mol Cell 2003;11:875-884.

31. Hargreaves D, Santos-Sierra S, Giraldo R, Sabariegos-Jareno R, de la Cueva-Mendez G, Boelens R, Diaz-Orejas R, Rafferty JB. Structural and functional analysis of the kid toxin protein from E. coli plasmid R1. Structure (Camb) 2002;10:1425-1433.

32. van den Heuvel RH, Heck AJ. Native protein mass spectrometry: from intact oligomers to functional machineries. Curr Opin Chem Biol 2004;8:519-526.

33. Sobott F, Robinson CV. Protein complexes gain momentum. Curr Opin Struct Biol 2002;12:729-734.

34. Giraldo R, Andreu JM, Diaz-Orejas R. Protein domains and conformational changes in the activation of RepA, a DNA replication initiator. EMBO J 1998;17:4511-4526.

35. Delaglio F, Grzesiek S, Vuister GW, Zhu G, Pfeifer J, Bax A. NMRPipe: a multidimensional spectral processing system based on UNIX pipes. J Biomol NMR 1995;6:277-293. 
36. Johnson BA, Blevins RA. NMRView: a computer program for the visualization and analysis of NMR data. J Biomol NMR 1994; 4:603-614.

37. Cornilescu G, Delaglio F, Bax A. Protein backbone angle restraints from searching a database for chemical shift and sequence homology. J Biomol NMR 1999;13:289-302.

38. Mulder FA, van Tilborg PJ, Kaptein R, Boelens R. Microsecond time scale dynamics in the RXR DNA-binding domain from a combination of spin-echo and off-resonance rotating frame relaxation measurements. J Biomol NMR 1999;13:275288.

39. Fiser A, Do RK, Sali A. Modeling of loops in protein structures. Protein Sci 2000;9:1753-1773.

40. Laskowski RA, MacArthur MW, Moss DS, Thornton JM. PROCHECK: a program to check the stereochemical quality of protein structures. J Appl Cryst 1993;26:283-291.

41. Tahallah N, Pinkse M, Maier CS, Heck AJ. The effect of the source pressure on the abundance of ions of noncovalent protein assemblies in an electrospray ionization orthogonal time-offlight instrument. Rapid Commun Mass Spectrom 2001;15:596601.

42. Schmidt A, Bahr U, Karas M. Influence of pressure in the first pumping stage on analyte desolvation and fragmentation in nano-ESI MS. Anal Chem 2001;73:6040-6046.
43. Dao-Thi MH, Charlier D, Loris R, Maes D, Messens J, Wyns L, Backmann J. Intricate interactions within the ccd plasmid addiction system. J Biol Chem 2002;277:3733-3742.

44. Lah J, Simic M, Vesnaver G, Marianovsky I, Glaser G, EngelbergKulka H, Loris R. Energetics of structural transitions of the addiction antitoxin MazE: is a programmed bacterial cell death dependent on the intrinsically flexible nature of the antitoxins? J Biol Chem 2005;280:17397-17407.

45. Loris R, Dao-Thi MH, Bahassi EM, Van Melderen L, Poortmans F, Liddington R, Couturier M, Wyns L. Crystal structure of CcdB, a topoisomerase poison from E. coli. J Mol Biol 1999;285:16671677.

46. Dao-Thi MH, Van Melderen L, De Genst E, Afif H, Buts L, Wyns L, Loris R. Molecular basis of gyrase poisoning by the addiction toxin CcdB. J Mol Biol 2005;348:1091-1102.

47. Koradi R, Billeter M, Wuthrich K. MOLMOL: a program for display and analysis of macromolecular structures. J Mol Graph 1996; 14:51-55.

48. Afif $\mathrm{H}$, Allali N, Couturier M, Van Melderen L. The ratio between $\mathrm{CcdA}$ and $\mathrm{CcdB}$ modulates the transcriptional repression of the ccd poison-antidote system. Mol Microbiol 2001;41:73-82.

49. Santos-Sierra S, Giraldo R, Diaz-Orejas R. Functional interactions between homologous conditional killer systems of plasmid and chromosomal origin. FEMS Microbiol Lett 1997;152:51-56. 